\title{
Sakubitril/valsartan'ın kardiyak tersine yeniden şekillenmeye etkisi var mı?
}

\section{Dr. Dilek Yeşilbursa}

Uludağ Üniversitesi Tıp Fakültesi, Kardiyoloji Anabilim Dalı, Bursa

Miyosit hasarı veya kaybından sonra, hemodinamik yüklenmeye ve eşlik eden nörohumoral faktörlere bağlı olarak kardiyomiyosit düzeninde ve ekstraselüler matriks yapısında birtakım değişiklikler başlar. Bunun sonucunda kalbin boyutlarında, şeklinde, yapısında ve fonksiyonlarında oluşan değişikliklere remodeling (yeniden şekillenme) denir. Sol ventrikül geometrisi giderek artan dilatasyona ve hipertrofiye bağlı olarak değişir, ventrikül daha sferik bir şekil alır. Kardiyak dilatasyon kötü prognozun önemli bir göstergesidir. Tam tersine ventrikül dilatasyonunun gerilemesi ise iyi prognozla ilişkilidir.

Kalp yetersizliği (KY) tedavisinin kısa dönemdeki amaçları, semptomları kontrol altına alıp, hayat kalitesini arttırmaktır. Uzun dönemde ise KY'nin karakteristik özelliği olan progresif sol ventrikül disfonksiyonunu yavaşlatarak, durdurarak veya geriye döndürerek yaşam süresini arttırmak amaçlanır.

Ventrikülde meydana gelen yeniden şekillenme sürecine ACE inhibitörleri ve beta-blokerler gibi farmakolojik ajanların yaptığg olumlu etkiler bilinmektedir. Bu ilaçlar ventrikül geometrisini ve fonksiyonunu düzelterek KY hastalarında morbidite ve mortaliteyi azaltırlar.

Kardiyak resenkronizasyon tedavisinin düşük ejeksiyon fraksiyonlu KY (DEFKY) ve ventrikül içi ileti gecikmesi olan hastalarda semptomları azaltmasının yanı sıra sol ventrikül diyastol ve sistol sonu hacimlerini ve sol ventrikül kas kitlesini azalttığ 1 yapılan çalışmalarda gösterilmiştir. Bu bulgular kardiyak resenkronizasyon tedavisinin hemodinamik iyileşme ile birlikte kalpteki tersine yeniden şekillenme ile ventrikül fonksiyonlarını iyileştirerek mortalitede azalma sağladığgnı göstermektedir.

PARADIGM HF çalışmasında, anjiyotensin-reseptör neprilisin inhibitörü (ARNI) olan sakubitril/ valsartanın DEFKY'de etkinlik ve güvenirliği bir ACE inhibitörü olan enalapril ile karşılaştırılarak test edilmiştir. ${ }^{[1]}$ Çalışma sonuçları, sakubitril/valsartanın, enalaprile göre kardiyovasküler mortalite veya KY'ne bağlı hastaneye yatışları azalttığını göstermiştir. Daha sonra yapılan analizlerde sakubitril/valsartanın enalaprile göre NYHA sınıfında daha fazla düzelme sağladı $\breve{g} 1$, takipte ilave tedaviye daha az ihtiyaç duyuldu$\breve{g u}, \mathrm{KY}$ nedeniyle acil servise başvuran hasta sayısı ile başvuru sayısının daha az olduğu, yoğun bakıma yatışların, yoğun bakımda kalış süresinin ve IV inotropik tedavi ihtiyacının daha az olduğu tespit edilmiştir. Bununla birlikte, ARNI'nin kardiyak tersine yeniden şekillenme üzerindeki etkisi PARADIGM-HF çalışmasında değerlendirilmemiştir.

2010-2019 yılları arasında yapılan 20 çalışmanın ele alındığı bir meta analizde 5696 ARNI alan, 4479 ACE inhibitörü veya anjiyotensin reseptör blokeri (ARB) alan toplam 10175 hasta değerlendirilmiştir. ${ }^{\text {[2] }} \mathrm{Bu}$ çalışmaların 18'i DEFKY hastalarında, 1'i hipertansiyon hastalarında biri de korunmuş ejeksiyon fraksiyonlu KY hastalarında yapılmıştır (Tablo 1). Meta analize dahil edilen 20 çalışmanın 4'ü RKÇ, 16'sı ise RKÇ değildir. Bu çalışmaların 9'unda EF, 7 'sinde NYHA fonksiyonel sınıf, diyastol sonu hacim ve çap, 6 çalışmada sistol sonu hacim, 6 çalışmada NT-proBNP düzeylerine bakılmıştır. Toplanan sonuçlar DEFKY hastalarında ARNI ile ACE inhbitörü veya ARB'ye kıyasla tüm parametrelerde anlamlı iyileşmeler olduğunu göstermiştir. Bu meta analizin sonuçları; ARNI'nin ACE inhibitörleri veya ARB'lere kıyasla sol ventrikül boyutlarını belirgin şekilde iyileştirdiğini ve ARNI ile tedavi edilen hastalarda kardiyak tersine yeniden şekillenmede görülen bu olumlu etkinin 3 ay gibi kısa sürede görüldüğünü desteklemektedir.

EVALUATE-HF çalışmasında; 464 DEFKY hastasında, sakubitril/valsartan ile ACE inhibitörü olan enalaprilin aort sertliği ve kardiyak yeniden şekillenme üzerindeki etkisi araştırılmıştır. ${ }^{[3]}$ Sakubitril/valsartan ile enalaprile göre 12 . haftada aort sertliğinde azalma 
Tablo 1. Meta analize dahil edilen çalışmaların ve hastaların özellikleri[ ${ }^{2]}$

\begin{tabular}{|c|c|c|c|c|c|c|c|c|c|}
\hline Yazar-Yıl & $\begin{array}{l}\text { Çalışma } \\
\text { dizaynı }\end{array}$ & $\begin{array}{l}\text { Kullanılan } \\
\text { ilaçlar }\end{array}$ & $\begin{array}{l}\text { Hasta } \\
\text { sayısı }\end{array}$ & Durum & Yaş & $\begin{array}{c}\text { Erkek } \\
(\%)\end{array}$ & Görüntüleme & Göstergeler & $\begin{array}{c}\text { Takip } \\
\text { (ay) }\end{array}$ \\
\hline \multicolumn{10}{|c|}{ Randomize kontrollü çalışma } \\
\hline $\begin{array}{l}\text { McMurray } \\
2014\end{array}$ & $\mathrm{RKÇ}$ & $\begin{array}{c}\text { ARNI } \\
\text { Enalapril }\end{array}$ & 8399 & $\begin{array}{c}\text { DEFKY } \\
(\mathrm{EF} \leq \% 35)\end{array}$ & $63.8 \pm 11.39$ & 78.1 & EKO & Biyobelirteç & 27 \\
\hline $\begin{array}{l}\text { Schmieder } \\
2016\end{array}$ & RKÇ & $\begin{array}{c}\text { ARNI } \\
\text { Olmesartan }\end{array}$ & 114 & $\mathrm{HT}$ & $59.81 \pm 10$ & 67.5 & KMRG & $\begin{array}{c}\text { KTYŞ } \\
\text { göstergeleri }\end{array}$ & 13 \\
\hline $\begin{array}{l}\text { Solomon } \\
2012\end{array}$ & RKÇ & $\begin{array}{c}\text { ARNI } \\
\text { valsartan }\end{array}$ & 301 & $\begin{array}{c}\text { KEFKY } \\
(E F \geq \% 45)\end{array}$ & $71.0 \pm 9.15$ & 43.5 & EKO & $\begin{array}{l}\text { FK, KTYŞ } \\
\text { göstergeleri, } \\
\text { Biyobelirteç }\end{array}$ & 9 \\
\hline $\begin{array}{l}\text { Kang } \\
2018\end{array}$ & RKÇ & $\begin{array}{c}\text { ARNI } \\
\text { valsartan }\end{array}$ & 118 & DEFKY & $62.6 \pm 11$ & 61 & EKO & $\begin{array}{c}\text { KTYŞ } \\
\text { göstergeleri }\end{array}$ & 12 \\
\hline $\begin{array}{l}\text { Almufleh } \\
2017\end{array}$ & Kohort & $\begin{array}{c}\text { ARNI } \\
\text { ACEI/ARB }\end{array}$ & 49 & DEFKY & $70 \pm 11.1$ & 79.2 & EKO & $\begin{array}{l}\text { FK, KTYŞ } \\
\text { göstergeleri }\end{array}$ & 3 \\
\hline $\begin{array}{l}\text { DeDiego } \\
2018\end{array}$ & Kohort & $\begin{array}{l}\text { ARNI } \\
\text { ramipril }\end{array}$ & 250 & $\begin{array}{c}\text { DEFKY } \\
(E F \leq \% 40)\end{array}$ & $69 \pm 8$ & 76 & EKO & $\begin{array}{l}\text { FK, KTYŞ, } \\
\text { göstergeleri } \\
\text { Biyobelirteç }\end{array}$ & 6 \\
\hline $\begin{array}{l}\text { Nazzari } \\
2017\end{array}$ & Kohort & $\begin{array}{c}\text { ARNI } \\
\text { ACEI/ARB }\end{array}$ & 43 & DEFKY & $58.0 \pm 12.9$ & $\begin{array}{l}\text { Bilgi } \\
\text { yok }\end{array}$ & EKO & $\begin{array}{l}\text { FK, KTYŞ } \\
\text { göstergeleri }\end{array}$ & 6 \\
\hline \multicolumn{10}{|c|}{ Randomize kontrollü çalışma değil } \\
\hline $\begin{array}{l}\text { Barrett } \\
2018\end{array}$ & $\begin{array}{c}\text { Gözlemsel } \\
\text { çalışma }\end{array}$ & ARNI & 61 & DEFKY & 68 & 65 & EKO & Biyobelirteç & 3.4 \\
\hline $\begin{array}{l}\text { Murray } \\
2017\end{array}$ & $\begin{array}{c}\text { Gözlemsel } \\
\text { çalışma }\end{array}$ & ARNI & 112 & DEFKY & $\begin{array}{l}\text { Bilgi } \\
\text { yok }\end{array}$ & $\begin{array}{l}\text { Bilgi } \\
\text { yok }\end{array}$ & EKO & Biyobelirteç & 18 \\
\hline $\begin{array}{l}\text { Maurin } \\
2017\end{array}$ & Kohort & ARNI & 80 & Sistolik KY & 59 & 76 & EKO & $\begin{array}{l}\text { FK, KTYŞ } \\
\text { göstergeleri }\end{array}$ & 3 \\
\hline $\begin{array}{l}\text { Canu } \\
2017\end{array}$ & $\begin{array}{c}\text { Gözlemsel } \\
\text { çalışma }\end{array}$ & ARNI & 200 & Sistolik KY & 59 & 81 & EKO & $\begin{array}{c}\text { FK } \\
\text { göstergeleri }\end{array}$ & 6 \\
\hline $\begin{array}{l}\text { Martens } \\
2018\end{array}$ & Kohort & ARNI & 125 & $\begin{array}{c}\text { DEFKY } \\
(\mathrm{EF}<\% 35)\end{array}$ & $66 \pm 10$ & 81 & EKO & $\begin{array}{c}\text { FK, KTYŞ } \\
\text { göstergeleri }\end{array}$ & 4 \\
\hline $\begin{array}{l}\text { Groba-Marco } \\
2018\end{array}$ & $\begin{array}{c}\text { Gözlemsel } \\
\text { çalışma }\end{array}$ & ARNI & 17 & $\begin{array}{c}\text { Semptomatik } \\
\text { DEFKY }\end{array}$ & $60 \pm 10.9$ & 76 & EKO & $\begin{array}{l}\text { FK, KTYŞ } \\
\text { göstergeleri }\end{array}$ & 4.9 \\
\hline $\begin{array}{l}\text { Kalantari } \\
2018\end{array}$ & $\begin{array}{c}\text { Gözlemsel } \\
\text { çalışma }\end{array}$ & ARNI & 40 & DEFKY & $\begin{array}{l}\text { Bilgi } \\
\text { yok }\end{array}$ & $\begin{array}{l}\text { Bilgi } \\
\text { yok }\end{array}$ & EKO & $\begin{array}{c}\text { FK, KTYŞ } \\
\text { göstergeleri }\end{array}$ & 3 \\
\hline $\begin{array}{l}\text { Mercedes } \\
\text { Faraudo } \\
2017\end{array}$ & $\begin{array}{c}\text { Gözlemsel } \\
\text { çalışma }\end{array}$ & ARNI & 23 & DEFKY & 71 & 91 & EKO & FK göstergeleri & 3 \\
\hline $\begin{array}{l}\text { Rafael Bravo } \\
\text { Marques } \\
2017\end{array}$ & $\begin{array}{c}\text { Gözlemsel } \\
\text { çalışma }\end{array}$ & ARNI & 57 & DEFKY & $69 \pm 10$ & 80.7 & EKO & $\begin{array}{l}\text { FK, KTYŞ } \\
\text { göstergeleri }\end{array}$ & 12 \\
\hline $\begin{array}{l}\text { Hlavata } \\
2018\end{array}$ & $\begin{array}{c}\text { Gözlemsel } \\
\text { çalışma }\end{array}$ & ARNI & 12 & DEFKY & Bilgi yok & 91.7 & EKO & FK, biyobelirteç & 3 \\
\hline $\begin{array}{l}\text { Beltran } \\
2018\end{array}$ & $\begin{array}{c}\text { Gözlemsel } \\
\text { çalışma }\end{array}$ & ARNI & 58 & DEFKY & $70 \pm 11$ & 72.4 & EKO & FK göstergeleri & 3 \\
\hline $\begin{array}{l}\text { Rodil Fraile } \\
2018\end{array}$ & $\begin{array}{c}\text { Gözlemsel } \\
\text { çalışma }\end{array}$ & ARNI & 65 & DEFKY & $78.6 \pm 7.4$ & 68 & EKO & FK göstergeleri & 9.5 \\
\hline $\begin{array}{l}\text { Mantis } \\
2018\end{array}$ & $\begin{array}{c}\text { Gözlemsel } \\
\text { çalışma }\end{array}$ & ARNI & 52 & DEFKY & $64 \pm 11$ & 69 & EKO & FK göstergeleri & 6 \\
\hline
\end{tabular}


Tablo 2. Düşük ejeksiyon fraksiyonlu kalp yetersizliğinde kanıta dayalı tedavilerin kardiyak tersine yeniden şekillenmeye etkisi

\begin{tabular}{lccc}
\hline İlaçlar & SVEF'da artış, (\%) & SVEDV'de azalma (mL) & SVESV'de azalma (mL) \\
\hline ACEi (SOLVD-12 ay) & +4 & -13 & -13 \\
BB (metoprolol-3 ay) & +9 & -13 & -26 \\
MRA (spironolakton-4 ay) & +3 & -14 & - \\
İvabradin (SHIFT-8 ay) & +2.4 & -8 & -7 \\
KRT (MADIT-CRT-8 ay) & +11 & -21 & -32 \\
ARNI (PROVE-HF-12 ay) & +9.4 & -12 & -15 \\
\hline
\end{tabular}

BB: Beta-bloker; SVEF: Sol ventrikül ejeksiyon fraksiyonu; SVEDV: Sol ventrikül diyastol sonu volüm; SVESV: Sol ventrikül sistol sonu volüm; MRA: Mineralokortikoid reseptör antagonisti; KRT: Kardiyak resenkronizasyon tedavisi; ARNI: Anjiyotensin-reseptör neprilisin inhibitörü.

saptanmamıştır. Sol ventrikül diyastol sonu ve sistol sonu hacimleri, sol atriyal hacim ve mitral E/e' oranı dahil olmak üzere ekokardiyografik son noktalarda sakubitril/valsartan ile önemli azalmalar görülmüştür. $\mathrm{Bu}$ da kardiyak yeniden şekillenme ve tahmini dolum basınçlarında iyileşme olduğunu göstermektedir. Ancak kontraktiliteyi gösteren parametrelerde (sol ventrikül ejeksiyon fraksiyonu, global longitudinal strain) veya ventriküler vasküler eşleşmede (coupling) (Ea/Ees oranı) fark saptanmamıştır. Bu olumlu kardiyak yapısal değişiklikler, NTproBNP'deki azalmaya ve yaşam kalitesindeki iyileşmelere paralel olmuştur. $\mathrm{Bu}$ veriler DEFKY hastalarında enalapril ile karşılaştırıldığında sakubitril/valsartanın klinik yararlarının, muhtemelen santral aort sertliği veya pulsatil yükteki değişikliklerle ilgisi olmadığını, buna karşın neprilisin inhibisyonunun miyokardiyal yeniden şekillenme ve duvar stresi üzerindeki olumlu etkilerine bağlı olduğunu düşündürmüştür.

PROVE-HF çalışması sakubitril/valsartan ile tedavi edilen DEFKY hastalarında NT-proBNP değişikliklerinin kardiyak hacim ve fonksiyon ölçümlerindeki değişikliklerle ilişkili olup olmadığını belirlemek amacıyla planlanmış prospektif gözlemsel bir çalışmadır. ${ }^{[4]}$ Çalışmaya 794 hasta dahil edilmiş ve 12 ay boyunca takip edilmişlerdir. Sacubitril/valsartan ile tedaviyi takiben NT-proBNP'de azalma sol ventrikül EF'de bir artış ve sol ventrikül ve sol atriyum hacimlerinde ve E/e' azalma ile ilişkili bulunmuştur. Bu parametrelerde iyileşme 6 ayda belirgin ancak 1 yılda daha belirgin olduğu görülmüştür. DEFKY hastalarında sakubitril/ valsartan ile görülen olumlu etkiler gözlenen tersine kardiyak yeniden şekillenme ile açıklanabilir.

Miyokardiyal fibrozis, KY'nin gelişmesinde önemli bir yeri olan patofizyolojik mekanizmadır. Ventriküllerin yapısal özelliklerinin belirlenmesinde intertisyel bağ dokusu önemli rol oynar. Kardiyak remodeling sirasında fibriler kollajen sentezinde ve y1kımında önemli değişiklikler olur. Kollajen çapraz bağlantılar değişirken, miyosit ile bağlantılı kollajen strutta kayıp izlenir. KY'de mekanik stres ve nörohumoral aktivasyon fibroblastları daha fazla kollajen üretmeleri için aktive eder. Aşırı kollajen sentezi, fibrosiz artışına ve ventrikül fonksiyonlarında bozulmaya neden olur.

PARADIGM-HF çalışmasına dahil edilen 2067 hastada kollajen sentezinde ve yıkımında rolü olan 8 biyobelirteç (aldosteron, TIMP-1, MMP-2, MMP-9, sST2, Gal-3, PINP, PIIINP) tedavi öncesi ve tedaviden 8 ay sonra çalışılmıştır. ${ }^{[5]}$ Başlangıçta, profibrotik biyobelirteçler olan aldosteron, sST2, TIMP-1, Gal3 , PINP ve PIIINP düzeyleri daha yüksek, kollajen yıkımı ile ilişkili biyobelirteçler olan MMP-2 ve -9 düzeyleri yayınlanan referans kontrol değerlerinden daha düşük saptanmıştır. Randomizasyondan sekiz ay sonra aldosteron, sST2, TIMP-1, MMP-9, PINP ve PIIINP düzeyleri enalapril grubuna göre sakubitril/valsartan alan grupta daha düşük düzeyde olduğu görülmüştür. Başlangıçta, sST-2, TIMP-1 ve PIIINP değerlerinin daha yüksek olduğu hastalarda birincil sonlanım noktalarının daha yüksek olduğu, sST-2 ve TIMP-1 düzeylerinde başlangıçtan 8 aya kadar olan değişiklikler ile bu sonlanım noktalarının ilişkili olduğu saptanmıştır. Bu biyobelirteçlerdeki değişiklikler sakubitril/valsartanın DEFKY hastalarında görülen olumlu etkilerinin bir açıklaması olabilir.

Tablo 2'de DEFKY hastalarında kanıta dayalı tedavinin tersine yeniden şekillenme üzerine olan etkileri görülmektedir.

Sonuç olarak bu çalışmalar; ARNI'nin, ACE inhibitörü veya ARB'lere göre DEFKY hastalarında kardiyak tersine yeniden şekillenme üzerine olumlu etkisi olduğunu desteklemektedir. 


\section{Kaynaklar}

1. McMurray JJ, Packer M, Desai AS, Gong J, Lefkowitz MP, Rizkala AR, et al. Angiotensin-neprilysin inhibition versus enalapril in heart failure. N Engl J Med 2014;371:993-1004.

2. Wang Y, Zhou R, Lu C, Chen Q, Xu T, Li D. Effects of the Angiotensin-Receptor Neprilysin Inhibitor on Cardiac Reverse Remodeling: Meta-Analysis. J Am Heart Assoc 2019;8:e012272.

3. Desai AS, Solomon SD, Shah AM, Claggett BL, Fang JC, Izzo J, et al. Effect of Sacubitril-Valsartan vs Enalapril on Aortic Stiffness in Patients With Heart Failure and Reduced Ejection Fraction: A Rando- mized Clinical Trial. JAMA 2019;322:1-10.

4. Januzzi JL Jr, Prescott MF, Butler J, Felker GM, Maisel AS, McCague $\mathrm{K}$, et al. Association of Change in N-Terminal Pro-B-Type Natriuretic Peptide Following Initiation of Sacubitril-Valsartan Treatment With Cardiac Structure and Function in Patients With Heart Failure With Reduced Ejection Fraction. JAMA. 2019;322:1-11.

5. Zile MR, O'Meara E, Claggett B, Prescott MF, Solomon SD, Swedberg K, et al. Effects of Sacubitril/Valsartan on Biomarkers of Extracellular Matrix Regulation in Patients With HFrEF. J Am Coll Cardiol 2019;73(7):795-806. 